\title{
Secondary School Youths, Identity and the Curriculum
}

\author{
Dr. Martin Banda ${ }^{1^{*}}$, Mable Nowanga Sitali Tembo ${ }^{2}$ \\ ${ }^{1}$ Head of Department of Educational Psychology and Sociology of Education at Kwame Nkrumah University- \\ Zambia \\ ${ }^{2}$ Head of Department for Educational Administration and Policy Studies at Kwame Nkrumah University \\ *Corresponding Author: Martin Banda, Head of Department of Educational Psychology and Sociology \\ of Education at Kwame Nkrumah University-Zambia
}

\begin{abstract}
The question of identity has continued to attract considerable attention from scholars. The article accounts for the meanings of identity in feminine and masculine perspective in relation to the curriculum.

Identity is an unclear term often failing to contextualise; it has its roots from the Latin word idem, meaning same. However, the term implies both similarity and difference. It is something that distinguishes one from another.

According to Baumeister (1986), identity rests on the concept of self that is shared by the person, other people and society. Two main defining criteria in identity are continuity and differentiation. One must be the same today and overtime, people change but they should retain some continuity of identity. Additionally, there should be things or characteristics that distinguish someone from other people. Anything that furnishes continuity and differentiation helps to define identity. The article explores how the secondary school curriculum in Zambia facilitates the identity of the youths.
\end{abstract}

Behavioural differences between sexes increase with age because children's intellectual biases are being exaggerated by our gendered culture. Children do not inherit intellectual differences they learn them. They are a result of what a boy or girl is expected to be.

Keywords: 1) Curriculum, 2) Youths, 3) Identity, Socialisation, 4) Gender, 5) Secondary school.

\section{Wно Ам I?}

\subsection{Post-Secondary Perspectives}

In the following paragraphs, the writers of this paper endeavour to give a brief personal identity and the pupils' and students' point of view or understanding of who they think they are. All the participants gave a concise description about themselves (who am I?). These thoughts are given in line with each participants; understanding of the concept of identity (who each one thinks he/she really is and/or is perceived to be by others). As a guide to the shared thoughts, identities are the traits and characteristics, social relations, roles, and social group memberships that define who one is. Identities can be focused on the past (what used to be true of one), the present (what is true of one now), or the future (the person one expects or wishes to become), the person one feels obligated to try to become, and/or the person one fears one may become. Identities are orienting, they provide a meaning therebymaking lens and focus one's attention on some but not other features of the immediate context.

\subsubsection{Participant A}

I honestly do not think there is a good answer to this question, it all depends on whether or not I see myself through my own lens or I rely on other people's perceptions of me. None will be accurate. I am a different thing to different people. Some will think I am a friend, some will think I am an enemy; some will see me as that random person on the streets of Kwame Nkrumah University that always wears the same clothes. Others think that I am a person who always wears a smile on his face, that social person, whilst others will see me as that shy, funny, introverted, helpful and religious person.

I am who I think I am and what people say I am. I am Madalitso Chikondi (not real names), a fourth year student at Kwame Nkrumah university, pursuing a Bachelors of Business studies with Education, 
I am a Zambian young man, I am male because of the kind of genitals I possess, am human, because I have humanity in me.

I am that someone who has high expectations for my results. I am confident in my ability to produce, and while I prepare for the worst, I do the work required to incline the chances so that the best will happen. I am someone who wants to be judged by individual performance and remunerated for my efforts based on my ability to execute things. I am that person who wants to work for a successful company with strong leadership and vision, one that recognises and rewards performers.

I am a hard working person and that person who believes in teamwork, for the betterment of the work required to be done.

I am that someone who takes responsibility for their actions when things go wrong. I does not look for outside forces to blame; rather, I am someone who looks at what I can improve upon the next time around. I am that person who feels pointing fingers solves nothing.

\subsubsection{Participant $B$}

I am a flower quickly fading, here today and gone tomorrow. This is because throughout the history of humanity the subject of identity has sent composers to the blank page, people who ask this question are anxious with their identity and looking for care of themselves.

My identity is seen as an ongoing process rather than stagnant snapshot; I therefore, should embrace a flowing sense of self whereby I always re-framing, re-organising, re-thinking and re-considering. When the sense of inadequacy invades me, I often ask myself who am I. Hence, deepen myself understanding the complexity of my nature as the process of life unfolds.

However, witnessing my beliefs, not countering out of old habits and becoming present permit me to healthier craft my life. As such, the identity that I seek energises the wave of life, enriched by the flow. The goal then is to access that potential, keeping the portions of my individuality that continue to serve as well as shedding the old, habitual pieces that constrain me, this process is known as disintegration.

This permits me to find balance between the previous weaknesses and enter into a relationship with self that commit to own personal evolution mostly I ask myself, what is my identity? Iam a religious nun but the truth is that I am a religious sister because of God's call and providence. This dependent on something else who is God. Who am I then?

By not knowing the answer to the question, I keep on creating new identity of myself as a result drifting away from identity and mostly suffering in life is because of not knowing identity. Until I realise my true self, and believe myself to be the name that has been given to me. In reality,I am an eternal soul.

Again, my identity is being influenced by the nature of genes that am a woman with the features emerged at conception that differentiate me from men. These features give me identity that makes me to insulate or cling myself to the opposite sex. However, socialisation is being influenced by my identity because the environment where am being natured has strong impact on identity differences.

\subsubsection{Participant $C$}

Mpulumutsi Malupenga (not real names) are my full names and am a young Zambian lady by nationality aged 23 years old, the eighth born in a family of nine. Am Tonga by ethnicity from the Southern part of the country and Monze to be specific. To reach where I am; it would be prudent to say that I have had a blessing to experience life from different dimensions. To start with, a man who makes me view life different has raised me and I know what it means to have plenty and how it feels to have nothing. I have had an opportunity to visit various parts of our country and have mingled with various people from different walks of life which has allowed me to learn a lot things from them and has made me to be who I am now. Included in this paper are my hobbies, educational life and personality or rather to be specific my identity.

So far, I would be proud to say that my educational life has been an interesting journey because I have had a chance to go to a girl's school only and to a co-school that has allowed me to socialise with people of different identities. Did my primary school from Kalomo basic school, then completed my 
o-levels from St Mary's secondary school in Livingstone and now I am a fourth year student pursuing my Bachelor's Degree in Education at Kwame Nkrumah university one of the best institutions in Zambia. Up to now I wonder why people behave the way they do, it is the things that happen in the environment they are exposed to or the people they socialise with.I am a person who enjoys making friends because they give me a hand in times of need and they are always there to congratulate me when I do good things and above all give me direction in what we do which always motivates us to strive for greater heights. I value family so much, because they have seen me through thick and thin. Of course reading and watching movies cannot be left aside because they enrich my mind with new knowledge, which allows me to view the world from a different perspective. Cooking, travelling, cleaning, praying to mention only a few are also among my hobbies.

In short, I am a simple human being who appreciates life the way it is and have learnt that for one to be happy in this life one should socialise with other people.

\subsubsection{Participant $D$}

Iam who I am because I remember growing within the same body I have nowand I perceive that I have the same mind. When I ask myself how I know that am the same person I was as a baby, this is a question of persistence, which means my existence across time and how I can prove it. In other words, I perceive that my self persists through my life as the same human being because I have a soul, a timeless essence that continues in form even after the death of our living.

Am a female Zambian, Tonga by tribe from Southern Province. Am married and am a proud mother of 2 boys.Am dark in complexion and my hobbies are cooking, making friends and even reading. Most of the people will always tell me that am a difficult person to get along with but only those who are close to me are the only ones who can appreciate who I am.

When I was growing up my mother used to tell me that am different from my brother as am the only girl in a family of 8 . I was taught that boys and girls wear different types of clothes; thus dress marks the beginning of sex identity. As a girl, I was told to put on dresses and skirts where as my brother where given shirts and pairs of shorts. Am one person who respect and cook for my husband as my tradition states so. In the presence of men, a woman is expected to observe traditional female etiquette such as looking down and behaving humbly. As a result most people identify me as being Tonga by tribe because I look down when am in the presence of elderly people.

When am home, I spend most of the time with my family and on Sundays I spend the whole day at church specifically the United Church of Zambia (UCZ). However when am here at school, I spend most of my time on books as I want to do my best in all the courses. Above all I believe am a woman in that I have gone through the pain of giving birth to my children as agreeing with the writings of OUR ALMIGHTY GOD in Genesis 3:16, to the woman He said 'I will greatly increase your pains in childbearing and with pain you will give birth to children'. No man in my life time has gone through such not even carrying the baby in the womb for nine months; I believe this is what makes me a woman.

\subsubsection{Participant $E$}

In answering the question who am I? Firstly, I state the tone in which my response is given and thereafter, a brief description about who I think I am is given. The word identity as used today has two distinct but intertwined meanings, and that much of the force and interest of the concept turns on the implicit question of precisely how these meanings intertwine. The two senses may be designated social and personal identity. In the former, an identity is just a social category, a group of people designated by a label (or labels) that is commonly used either by the people designated, others, or both. This is the sense employed when we refer to African, French, Muslim, father, homosexual, worker, professor, or citizen as identities. Personal identity: this is the meaning invoked in declarations of the form my identity is ... or I could never do that because it would be inconsistent with, or would violate, my identity: Personal identity is a set of attributes, beliefs, desires, or principles of action that a person thinks distinguish him in socially relevant ways.

Thus, from the social context (who am I?): I am a human being of the dark coloured African race, a person among the peoples of the Southern Africa region. I am an endogenous Zambian, I am a Tonga by tribe from Southern Zambia; I am student at Kwame Nkrumah University in Kabwe-Zambia; In 
the silence of the cosmos, I am a student in a religious dominated world, I am a person of the Christian faith; I am so many things in the social context.

In the context of personal identity (who am I?). I am an introverted social-path as some have said of me. I am a student weighing between $70 \mathrm{kgs}$ and $80 \mathrm{kgs}$; I am a person who believes in the health reforms (an ideal diet should comprise of only vegetables and fruits); I am that person who listens attentively and make up my mind (own conclusion) based on my own understanding of the context. I am one kind of a person who can forgo something just to keep peace with my friends, I said to be a person good at friendship making yet have no way of maintaining friends. I am equally so many thingseven inthe personal identity context.

Furthermore, from the metacognitive context (who am I?): I am a person who makes swift judgements on any matter or issue.

\subsubsection{Participant $F$}

In order to get the best out of the pupil, the questions asked where deliberately kept simple to help the pupil grasp the idea or concept of identity (who am I?). Each off the members where tasked to perform a simple research from the various schools each did his/her teaching practice.

The results obtained are given in the following paragraphs below. To the question who am I? the pupil respondent:

In terms of gender identity I am a boy/girl, regarding tribe - I am (Tonga, Bemba, Ngoni, Kaonde, Lunda among others), in terms of race - I am an African a Zambian, in terms of religion - I am Christian.

Regarding other aspects, the pupils responded: I am a person who likes watching football, I like swimming, I like going out with friends, I am born from a family of four and I am number three, I am a person who likes chicken and chips, I am a friendly person among many other responses.

Furthermore, pupils responded that they are boys because they have a penis, testis; they are girls because they have breasts, and they give birth. Others simply said I am a boy/girl simply because of how I look.

\subsection{Analytical overview}

The above responses are generalised from their responses - most if not all respondents gave similar answers to the question of whom am I? This indicated the perception of who they are was strongly influenced by societal definition of the different attributes. Participants did not reason outside the "box" to really define who they are.

Socialisation between girls and boys is influenced by their identity differences. Boys and girls differ psychologically in the way they act, from the style in which they communicate to the way in which they attempt to influence others. These gender differences in communication and influence tactics also have implications in their socialisation activities.

According to (Van, \& Schein, 1979) defines socialisation as "a total process in which an individual acquires the attitudes, behaviours and knowledge needed to successfully participate as a school or organizational member." Socialisation is an ongoing process that sometimes lasts for a year. It represents a sense-making process that helps new hires adapt, form work relationships and find their place in the school or organisation. A typical socialisation process includes three phases,

\subsubsection{Anticipatory Socialisation}

This stage occurs before new members join the school or an organisation. Through interacting with representatives of that organisation or school, new members develop expectations about the organisation/school and the job prior to organisational entry.

\subsubsection{Encounter}

When new pupils/employees begin a new job, they start to learn about school/job tasks and receive training. Managers can exert their influence by helping new employees understand their roles and duties. Also, by understanding the stresses and issues that newcomers experience, managers can help cultivate a high-quality work relationship with newcomers. 


\subsubsection{Settling In}

New pupils/employees begin to feel comfortable with their new school/job demands and social relationships. They will be interested in the school/organisation evaluation of their performance and in learning about potential career opportunities within the school/organisation.

Influence can be defined as the capacity to have an effect on the character, development, or behaviour of someone or something, or the effect itself. Others also can define influence as the actions or process of producing effects on the actions and behaviour opinions. (http://www.dictionary.com accessed on Thursday 14:21)

Gender socialisation is a more focused form of socialisation, it is how children of different sexes are socialised into their gender roles and taught what it means to be male or female (Morris, 1988:366,Giddens, 1993:165). The socialisation of boys and girls is often analysed by sociologists to find out how and why males and females act differently in the society. The socialisation process begins at birth; thereby making families the primary agents of socialisation, families usually treat newly born babies in a different and unique way according to their sex (Peterson, et al 1999). Without a doubt, families begin to socialise sex roles even in the delivery rooms where babies are dressed according to the sex of that baby. For instance, boys are dressed in blue while girls are dressed in pink. From the moment that a baby enters the world it is busy with symbols and language that shapes its conception of gender roles and gender stereotypes (Burke, \& Peter J. 1989). As indicated in the table below.

\begin{tabular}{|l|l|}
\hline \multicolumn{1}{|c|}{ GENDER/SEX } & \multicolumn{1}{c|}{ COLORS } \\
\hline BOYS & BLUE \\
\hline GIRLS & PINK \\
\hline
\end{tabular}

The other traditional example of socialisation between that of boys and girls being influenced by their identity differences can be seen in the experiential observation, which was conducted in a certain community.The experiential observation was conducted to see how a baby when introduced canbe treated, the study was done in two parts the first being to see how a boy/male child is treated and the other part how girl/female is treated. The results were interesting and quite alarming at the same time. When the observation was being done, it was observed that participants who were playing with a baby boy; the child was offered toys, such as a hammer or rattle, while on the other hand participants playing with a baby girl; offered it a doll. It was further, observed that participants also touched the babies differently. In that, baby boys where often bounced, thus stimulating the whole body, whereas girls where touched gently and less forcefully the observation agrees with (Gleitman, Friedlund \& Reisberg, 2000).

In another study as indicated by (Giddens, 1993; 166), it was found out that words such as "sturdy", "handsome" and "tough" are used to describe boy infants and "dainty", "sweet" and "charming" for girl infants, although there were no differences in the sizes of the infants. These findings show that other people contribute a lot as we see ourselves only on the basis of gender. In the first case presented, the message that the participants were sending was that if the baby is a boy, he must play with hammers and such only because of his gender, while on the other hand girls have to play with dolls because they are girls. In the second case we can see that when people are referring or addressing boys the kind of words used tend to differ with that of girls as observed earlier on. Thereby bringing in the issue of language also being said to have an effect on the socialisation of boys and girls. For example as earlier alluded to the fact that language used by families to describe boys is usually centred on substantial characteristics and such themes as the ability to influence and liveliness, while the language that is appropriate to girls by families might address love, expressivity, neatness, or tenderness.

These different approaches and conduct of babies by the family serves to shape behaviour patterns and define restrictions. These restrictions are eventually internalised and become identity standards the references in which interactions, settings, and contexts are usedto compare the self to others (ibid).

Differences in gender are as a result of socialisation process, particularly throughout our childhood and adolescence. For instance, before we are 3 years old, there are attractive differences between how boys and girls interact (DeAngelis, 1989). Boys attempt to dominate, to control, to find out Am I better than you? They do this by little contests or by being violent, if necessary. Boys tend to create 
their status and then go ahead in trying to use power in order to improve their position in the "pecking order" (Ibid).

On the other hand, girls and women try to ascertain and improve their relationships, as if they were always asking "Do you like me?" Because boys and girls want to do different things, boys and girls start avoiding each other at three (3) or four (4) years. By the age 6, girls so dislike the forceful competitive play and authority by boys that they choose girls over boys as playmates. Little boys don't like "girl's games" either. Indeed, if asked, boys will express disgust at the idea of suddenly becoming girls; girls are not dismayed of becoming boys, they quickly recognise the advantages of being boys. Boys persistently want to win at active, competitive activities and seem less interested in "winning friends." Several studies have also found that older boys will comply with a male peer's suggestion but will stubbornly not comply with the same suggestion from a female peer. This is especially true if other males are watching (DeAngelis, 1989).

Schools are also said to be agents of socialisation, given that schools are social settings where gender and sexual identities are constructed, negotiated, and officially sanctioned, the overall educational environment offers influential messages about gender. The segregation of boys with that of girls in elementary school is a considerable component of childhood socialisation (Thorne, 1993). Teachers tend to use liberty measures that lay emphasis on gender division, though left to their own caution, students also chose to be separated by gender. In many countries, students sit in same sex pairs or groupings in the classroom (Warrington et al., 2000). Girls and boys often sit in split parts of the classroom and play in separate groups at indentation (as in Liberia, Brenner, 1998). In some instances, girls are regularly seated at the back of the classroom (Lewis \& Lockheed, 2006), but in others, such as Ghana, girls are not seated in back but dispersed around the classroom, either in small clusters or isolated among the boys (Anderson-Levitt et al., 1998).

Data from studies of large regional and international assessments indicate that the academic performance of girls and boys shows signs of convergence in the three areas most investigated: math, reading, and science (Ma, 2007). Internationally, the gender gap in mathematics has registered a reduction over time; there are small initial differences in favour of boys but by Grade 12 substantial asymmetries develop in favour of boys, although most recently, differences in favour of girls have appeared in several countries. Gender differences in reading continue to the advantage of girls but they are moderate. In science, small differences favour boys in grades four and five, but by grade 12 large to moderate differences in favour of boys have been observed across all countries, except South Africa (Ma, 2007). It should be noted that the largest gender gap in science can be considered moderate rather than strong. Yet, in both the U.K. and Australia, girls since the 1990s have been obtaining higher general scores in examinations given at the end of compulsory schooling.

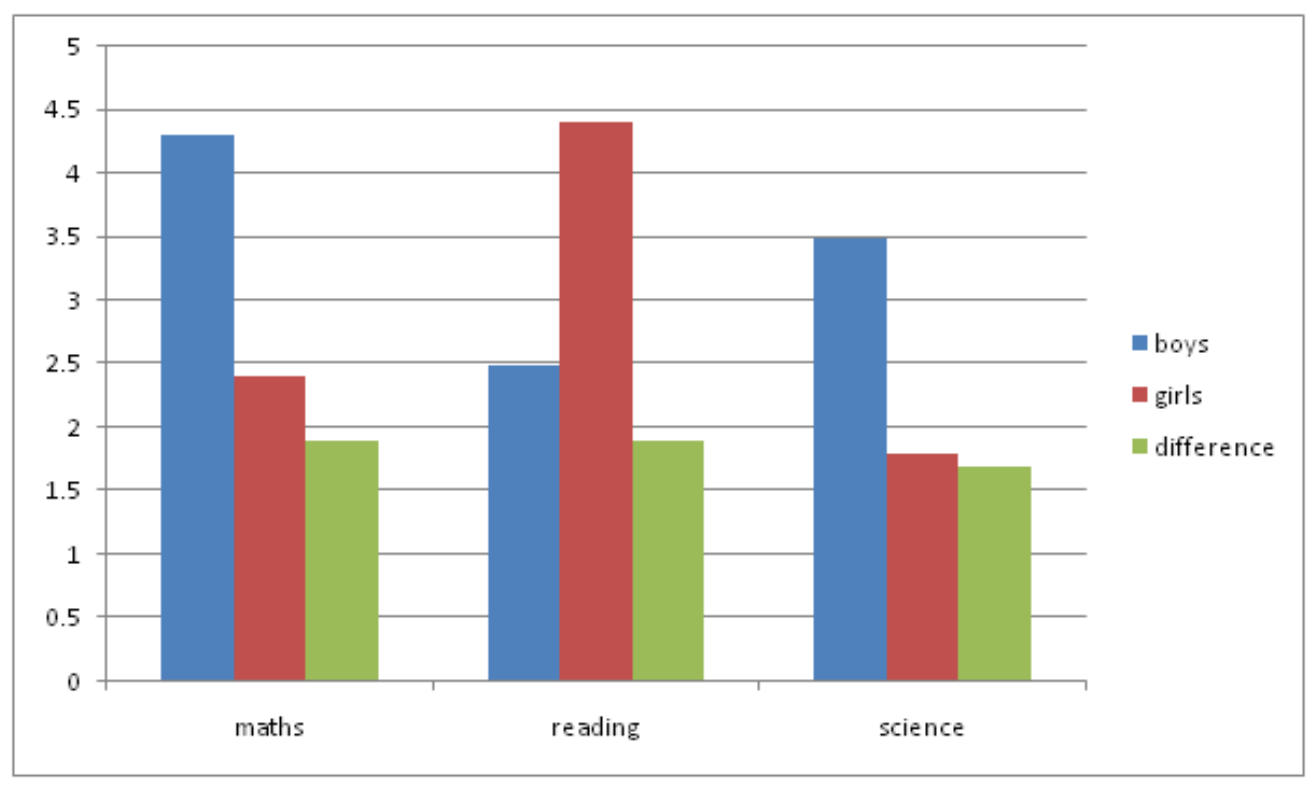

In line with the above data from large and international assessments, a research was carried out at some school in Solwezi District of Zambia that indicated how identity differences influence the socialisation between that of boys and that of girls. It was observed that girls at these schools are 
naturally said not to be good at mathematics and that boys are not good at reading. This was also seen in some optional subjects at this school. For example grade $11 \mathrm{~B}$ had Additional Mathematics and it was observed that very few girls were taking Additional Mathematics as their optional subject, and in $10 \mathrm{E}$ the optional subject was home management which had a good number of girls compared to boys.

\begin{tabular}{|l|l|l|}
\hline \multicolumn{1}{|c|}{ Subject } & \multicolumn{1}{c|}{ Boys } & \multicolumn{1}{c|}{ Girls } \\
\hline Home management & 15 & 45 \\
\hline Addition mathematics & 55 & 25 \\
\hline
\end{tabular}

It can therefore be said that, in as much as some subjects in schools are often seen to be in favour of boys or girls, that is how socialisation between boys and girls is affected. The table explains that in home management we have 5 boys and 25 girls meaning this subject is perceived to be a subject for girls therefore boys will find it hard to socialise with their opposite sex.

\subsection{Pupils' perspectives}

Generally most of the pupils said their socialisation at schools was greatly affected by the way things are done and structured at their various schools. Some pupils blamed the curriculum being of biased as some subject content are tough for ladies to appreciate for instance Additional Mathematics, all of the Industrial Arts subjects, some subjects are for girls said some boys; such as food and nutrition. Ideally, boys and girls in schools spend most of the times socialising with fellow boys and girls respectively. Others cited co-curricular activities which separated them most of the times; activities such as football for boys, netball only for girls. Some asserted to the fact that they learnt as boys and others as girls in separate schools which meant boys schools and girls schools: this affects the way the pupils generally socialised at schools as boys and girls.

\section{PERCEPTION OF THE SPREAd OF HIV AND AIDS AMONG SECONDARY SCHOOL YOUTHS}

The pupils attributed a number of factors as to how identity difference affects the perception of the spread of HIV among secondary schools. The identified factors have since explained as a way of adding meaning to the pupils understanding of things.

The role of culture has been particularly problematic in the fight against HIV/AIDS. HIV stands for Human Immune Virus and the late stage of HIV infection results in AIDS which stands for Acquired Immune Deficiency Syndrome. Culture, especially in the context of HIV/AIDS refers to society in which we live, as well as the gender inequalities which it has given rise to. Culture in general has facilitated the spread of HIV, with specific reference to cultural norms (gender roles and relations) and their potential contribution to the adoption of various practices, such as female genital mutilation, which may, in turn, lead to the further spread of HIV.

\subsection{Culture}

According to Braddy et al (2007), culture refers to the traditions and customs upheld by societies and communities because of their belief systems and values. Culture is defined as the learned, shared and transmitted values, beliefs, norms and life ways carried by groups of people, which guides their decisions, thinking and actions in patterned ways. The individual in society is bound by rules of his/her culture. Cultures are different in that the same events that may be fear-inducing in one culture may be anger-inducing in another.

Gender roles and relations also constitute some aspect of culture. These roles and relations arise out of a process of socialisation, where young secondary school boys and girls are taught their respective roles in society as well as in relation to one other. In black African culture, the male figure has always held the dominant position in the household. Agreeing withOak (2008) men in pre- colonial times were hunters and have always been the providers and breadwinners for their families. Women ploughed the fields and took care of the household duties which involved cooking, cleaning and washing clothes. It can be said that men have always maintained a 'superior' status over their wives to some degree. African boys are taught from a young age that they are to provide for their families and are to also be the 'heads' of their households. Young African girls, on the other hand, are socialised to become nurturers and caregivers to their children and husbands. They are to take care of their families and taught to be humble, as well as respectful to their husbands.

Furthermore, Oak (2008) states that lack of power by African women in relationships means that they have very limited decision-making abilities in the relationship and are unable to negotiate safer sex 
and therefore, risk infection to please the man. This is particularly the case if the woman's husband/partner is the sole breadwinner of the household, or if the woman has a low educational background. Her husband or partner may easily exploit her, resulting in her ultimately giving to all his needs and demands. HIV contraction has spread widely in such cases, especially as studies have revealed that some black African men prefer sexual intercourse without the use of a condom.

\section{Spread OF Hiv Among Secondary School PuPILS}

Young people are at the centre of the global HIV/AIDS pandemic. They are also the world's greatest hope in the struggle against this fatal disease. Today's youth have inherited a dangerous legacy that is killing them and their friends, their brothers and sisters, parents, teachers and role models. An estimated 11.8 million young people aged 15 to 24 are living with HIV/AIDS. Each day, nearly 6,000 young people between the ages of 15 and 24 become infected with HIV. Yet, only a fraction of them know they are infected as observed by Walker and Cornell (2004).

HIVspreads rapidly both within countries and across borders. It affects people regardless of gender, geography or sexual orientation. An interview conducted among secondary school youths resulted in the following reasons of spreading of HIV:

\subsection{Young People Have Sex}

Sexual activities begin in adolescence for the majority of people. In many countries, unmarried girls and boys are sexually active before the age of 15 . Recent surveys of boys aged 15 to 19 found that more than quarter reported having sex before they were 15. A study in Chipata found that 88 per cent of unmarried urban boys and 35 per cent of unmarried urban girls had engaged in sexual activity by the time they are 18.Adolescents who start having sex early are more likely to have sex with high-risk partners or multiple partners, and are less likely to use condoms. Delaying the age at which young people first havesex can significantly protect them from infection. Lacking the necessary knowledge and skills, adolescents are less likely to protect themselves from HIV than adults

\subsection{Young People Lack Information}

The research established that the vast majority of young people have no idea how HIV/AIDS is transmitted or how to protect themselves from the disease. More than 80 per cent of young women aged 15 to 24 do not have sufficient knowledge about HIV. An interview conducted at Chipata day secondary school showed that only 26 per cent of girls have heard of AIDS and only 1 per cent know how to avoid infection.

In one secondary school, pupils still believed they could screen out risky partners by looks alone. This misinformation is especially dangerous in a country where one of their potential sex partners are infected with HIV. Misconceptions about HIV/AIDS are widespread among young people. They vary from one culture to another, and particular rumours gain currency in some populations both on how HIV is spread (by mosquito bites or witchcraft, for example) and on how it can be avoided (by eating a certain fish, for example, or having sex with a virgin). Surveys indicate that more than 50 per cent of young people aged 15 to 24 harbour serious misconceptions about how HIV/AIDS is transmitted. (www.cdc.gov/hiv/group/age/youth/).

\subsection{Poverty and Out-of-School Youth}

Studies have found a direct relationship between higher AIDS incidence and lower income. In addition, studies have shown that the socioeconomic problems associated with poverty, including lack of access to high-quality healthcare, can directly or indirectly increase the risk for HIV infection. Research has shown that young people who have dropped out of school are more likely to become sexually active at younger ages and to fail to use contraception.

\subsection{Unprotected Sex}

Adolescents who are not yet sexually active must be encouraged to delay sexual activity. When young people do have sex, they must be able to protect themselves. Good-quality condoms have to be easily available and free or affordable. In some instances, however, knowledge about where to get a condom has declined; other young people may have information, but engage in unprotected sex because they lack the skills to negotiate abstinence or condom use. They may be fearful or embarrassed to talk with their partner about sex. Still others may not adopt safe behaviours because they perceive their individual risk to be low. 


\subsection{Girls are Very Vulnerable}

Though as a global average there are slightly more men infected with HIV than women, adolescent girls are at very high risk of getting infected. More than two thirds of newly infected 15- to 19-yearolds are female. There are a number of reasons why girls are becoming infected younger and dying earlier than boys are. The research has shown that 17 to 22 per cent of girls aged 15 to 19 are already HIV infected compared with 3 to 7 per cent of boys of similar age. This indicates a 'sexual mixing' pattern whereby older men are having sex with young girls. In our country for example where economic conditions make it difficult for girls to afford school fees, some seek favours of a sugar daddy (an older man who offers compensation in cash or kind in exchange for sexual favours), engage in transactional sex which is the exchange sex for money or goods on an occasional basis or enter sex work willingly or forced to pay for school, support their families or take care of themselves.

This 'age-mixing' is fuelled by the dangerous myth among men in some places that having sex with a virgin can 'cure' HIV. Many men also assume that younger girls are not yet infected. Cultural norms related to sexuality prevent many girls from taking active steps to protect themselves. In cultures where it is vital for girls to be virgins at marriage, some girls protect their virginity by engaging in unsafe sexual practices such as unprotected anal intercourse.

\subsection{Use of Drugs}

Adolescence is often a time of experimentation with drugs and alcohol. The survey showed that young people aged 16 to 24 who smoke and drink alcohol are four times more likely than their peers to have multiple sex partners. People who share needles and syringes for injecting drugs are at very high risk of contracting HIV. Secondary school youths who have sex under the influence of drugs or alcohol are more likely not to use protection.

\subsection{Children Orphaned or Affected By Aids}

There are a lot of children currently in Zambia that have lost one or both parents to AIDS. The total number of children orphaned by the epidemic is forecast to more than double by 2020.Children orphaned by AIDS are at greater risk of malnutrition, illness, abuse, child labour and sexual exploitation than children orphaned by other causes, and these factors increase their vulnerability to HIV infection. They also suffer the stigma and discrimination often associated with HIV/AIDS and may be denied education, work, housing and other basic needs.

\subsection{Feelings of Isolation}

Secondary school youths with a disability may engage in risky sexual behaviour and substance abuse because they feel isolated and luck of support. They are more likely to experience bully and other forms of violence which can lead to mental distress and engagement in risk behaviours that are associated with getting HIV.

\subsection{Female Circumcision}

Some youths interviewed brought up the issue of female circumcision as one of the spread of HIV among secondary school youths. Female circumcision is a euphemism for female genital mutilation.Kolucki (2007), states that although it is usually performed shortly before puberty in Africa, it has little relation with the practice of male circumcision and is not usually an initiation per se. female circumcision is in three types the first one involvespartial closure of the vagina. Excision involves the removal of clitoris and part of the labia minora. As a result of the procedures involved in female circumcision, it increases the likelihood of HIV transmission through increased exposure to blood in the vaginal canal. This is so because the presence of scar tissue and abnormal anatomy of the mutilated vagina would influence to numerous small tears in the mucosa during intercourse. (www.cirp.org/library/diseases/HIV/hrdy1/).

\subsection{Lack of Awareness}

Research has shown that a large proportion of young people are not concerned about becoming infected with HIV. Adolescents need accurate, age-appropriate information about HIV infection and AIDS, including the concept that abstinence is the only $100 \%$ effective way to avoid infection, how to talk with their parents or other trusted adults about HIV and AIDS, how to reduce and eliminate risk, 
how to talk with a potential partner about risk, where to get tested for HIV, and how to use a condom correctly.

\section{Perception OF THE PREVENTION OF HIV/AIDS AMONG SECONDARY SCHOOL YouthS}

Since the mid-eighties, the fight against HIV/AIDS has gradually mobilised governments, international agencies and non-governmental organisations. However, it became evidentthat despite massive action to inform the public about the risks, behavioural changes were notoccurring as expected. The infection continued to expand rapidly and serious questions began toemerge as to the efficiency of the efforts undertaken in combating the illness. Experience hasdemonstrated that the HIV/AIDS epidemic is a complex, multi-layered issue that requires close cooperationand therefore multidimensional strategies.HIV prevention in Africa must be embarked upon from different angles simultaneously, due to the sheer magnitude of the issue and the wide variety of circumstances in which people become infected. Attempts to stem the tide of the epidemic using approaches that rely on just one method of prevention have consistently failed, and will continue to fail. Therefore, this area will explain the preventive measures against HIV/AIDS among the secondary school youth.

The establishment of the Joint United Nations Program on HIV/AIDS (UNAIDS) in1994 initiated a new approach to the prevention and care of this disease. The first requirementis the need for improved co-ordination amongst institutions. An actionwas also madeon the need to work on both prevention and treatment while considering the significant social factorsinvolved. As a result UNAIDS was involved in several studies focusing on developing newmethodological strategies with which to grab the issue.Following a proposal made by UNESCO's Culture Sector to the UNAIDS Program, ontaking a cultural approach to HIV/AIDS prevention and treatment for sustainable development, ajoint project "A Cultural Approach to HIV/AIDS:

In the area of preventive education againstHIV/AIDS and drug abuse, UNESCO's activities over thelast two years have been mainly concerned with helping Member States prepare and set up programmesfor curriculum planners, teachers, young people (both in and out-of-school), and illiterate young women.Strategic guidelines and culturally appropriate prototype educational materials were researched anddesigned, in order to make them accessible to the specific target groups. During the next two years,special attention will be given to youth empowerment through preventive education against HIV/AIDS. Assisting national health educational systems in teacher training and curriculum developmentprogrammes and undertaking international campaigns for and by youth will realise this effort.

In its new strategy for preventive education in response to HIV/AIDS, UNESCO acknowledged fresh benchmarks and priorities for improving preventive education. In particular, it paid specific attention to evaluatingthe effectiveness of existing preventive education strategies and the generalisation of the best practices.Emphasis is placed on changing risk behaviour through the promotion of formal and informaleducation programmes directed towards pupils, university students, out-of-school youth and adults.These programmes will be complemented by more intensive campaigns using different media,including booklets, press information and radio messages in an effort to mobilise opinion leaders. This will help develop positive self-identity in spite of the stigma associated with being boy or girl in the times of HIV/AIDS.

It is globally accepted that knowing your status can help prevent HIV/AIDS transmission. This is the key step in making a decision on your health, in other words knowing your status means that you could make choices that can prevent the person around you from contracting the virus (that is if you are infected). As no scientifically proven cure exists for HIV/AIDS the universally accepted means of handling the pandemic is prevention. Prevention of HIV/AIDS aims to reduce the risk of infection by encouraging individuals to make healthy sexual life choices.Hence, in the $21^{\text {st }}$ century prevention is seen in the context of abstinence, being faithful, and wearing a condom (ABC). The question is how many youths pay attention to these rhetoric that are generally contrived and foist by the media?

The role of culture therefore, has been predominantlytricky in the fight against HIV/AIDS. When one talksof culture, especially in the context of HIV/AIDS, what comes to mind is the patriarchal society in which we live, as well as the gender inequalitieswhich it has given rise to. Hence, the diagram below explains how culture comes in with regards prevention of this virus. 


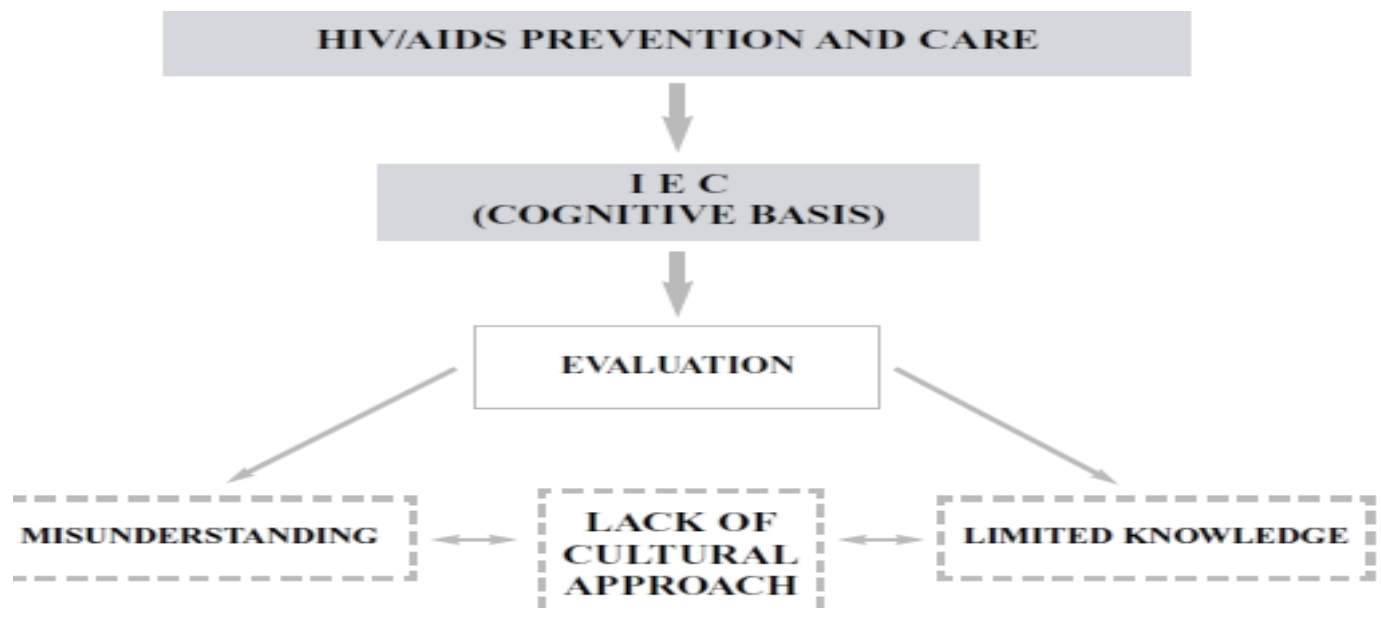

Still, gender roles and relations institute someaspect of culture. These roles and relations ariseout of a process of socialisation, where young boysand girls are taught their one-to-one roles in societyas well as in relation to one other. In black Africanculture, the male figure has always held thedominant position in the household. Men in pre-colonialtimes were hunters and have always beenthe providers and breadwinners for their families. Women ploughed the fields and took care of thehousehold duties which involved cooking, cleaningand washing clothes. It can be said thatmen have always maintained a 'superior' statusover their wives to some degree. African boys aretaught from a young age that they are to providefor their families and are to also be the 'heads' oftheir households.

Nevertheless, Young African girls, on the otherhand, are socialised to become nurturers and caregiversto their children and husbands. They are totake care of their families and taught to be humble,as well as respectful to their husbands. Thisis common knowledge among black Africans andthese patterns of socialisation are not only taught,but learned through daily observation withinone's family and other black African families. Asa result, the gender roles learned and adopted byyoung boys and girls influence the ways in whichthey relate to one another later in life. Men arelabelled 'provider/head' and women 'caregiver/subordinate'and, as a result, begin to internalise and assume these respective roles.

It can be argued that these gender differences/ inequalities contribute to the spread of sexually transmitted diseases, such as HIV/AIDS, in thatunequal power relations also come to exist when it comes to sexual intercourse. This, they felt, entitled them to various sexual partners, ultimately creating an opportunity in which to relieve, sexually, the stress and tension they experienced on a daily basis, thus simultaneouslyproviding an avenue in which to expresstheir manliness.Masculinity has been cited as 'a place in gender elations, the practices through which menand women engage that place in gender, and theeffects of these practices in bodily experience,personality and culture.' It has been posited thatpower imbalance, pervade all social relationshipsbetween men and women. To contextualisethis even more, there is an unequal balance ofpower between men and their sexual partners - animbalance whose detrimental effects have resultedin [black] women becoming the face of HIV/AIDS,

Lack of power byAfrican women in relationships means that theyhave very limited decision-making abilities inthe relationship and are unable to negotiate safersex and, therefore, risk infection to please theman. This is particularly the case if the woman'shusband/partner is the sole breadwinner of thehousehold, or if the woman has a low educationalbackground. Her husband or partner may easilyexploit her, resulting in her, ultimately, giving into all his needs and demands. HIV contraction hasspread widely in such cases, especially as studieshave revealed that some black African men prefersexual intercourse without the use of a condom.

It can be seen how these conditions themselvescould have created an environment conduciveto the practice of female genital injury as a way of ensuring maximum pleasure for men duringsexual intercourse. This suggests that highlypatriarchal African societies may have created anenvironment which spearheaded the adoption ofthis practice, by way of maintaining men's 'superior' statuses and, consequently, finding ways forwomen to please them. This sheds some degreeof light on how culture contributes to the spreadof HIV/AIDS, thus at once creating an environmentconducive to practices such as femalegenital mutilation (FGM), which further facilitate the spread of this epidemic. 
Currently most AIDS prevention programs in Africa are based on social values that value virginity for young people and monogamy and mutual fidelity for married persons. However such prevention programs may not be suitable for all ethnic groups (Gausser; 2001). National AIDS campaigns such as - ABC Abstinence Being faithful and correct use of Condoms. Offer choices for individuals who are sexually active. However, certain values are finagled when AIDS prevention messages emphasise abstinence and faithfulness over condom use without facing the realities of morality. Cultures that accept the aforementioned social values may find success with such AIDS prevention strategies because they are acceptable within the culture context of the target population. Thus, cultures that do not share go against their way have a more difficult time adopting strategies that go against their way of life.

It is important to note here that a condom-only stance to HIV prevention in Africa will not work either as it can be seen in the diagram illustrated below;

\begin{tabular}{|l|l|l|}
\hline \multicolumn{3}{|c|}{ REASONS FOR NON-USE OF CONDOMS } \\
\hline Perceptions & No of participants & Percentages \\
\hline DO NOT LIKE USING IT & 34 & 49 \\
\hline NOT AVAILABLE AT TIME OF COITUS & 22 & 31 \\
\hline CANNOT AFFORD COST & 5 & 7 \\
\hline NO REASON & 9 & 13 \\
\hline
\end{tabular}

Similarly, neither will education campaigns, implemented as a single pronged approach. HIV prevention in Africa must be tackled from different angles concurrently, due to the absolutedegree of the issue and the wide diversity of circumstances that people become infected. Attempts to stem the tide of the epidemic using approaches that rely on just one method of prevention have constantly failed, and will continue to fail. Approaches that address HIV prevention on multiple levels have proven to be far more effective. The $\mathrm{ABC}$ approach, for example, promotes abstinence, being faithful and using condoms, and has had a definite positive impact when implemented correctly. According to the table below it outlines how the $\mathrm{ABC}$ approach can work with a lot of sensitisation of the youths.

\begin{tabular}{|l|l|l|}
\hline \multicolumn{3}{|c|}{ PARTNERS OF SEXUALLY ACTIVE YOUTHS } \\
\hline PARTNER & FREQUENCY & $\%$ \\
\hline FRIENDS & 50 & 71 \\
\hline CASUAL ACQUAINTANCES & 11 & 16 \\
\hline TEACHERS & 5 & 7 \\
\hline RAPE & 4 & 6 \\
\hline TOTAL & 70 & 100 \\
\hline
\end{tabular}

Despite the overwhelming evidence confirming that single-pronged prevention campaigns do not work, there are still those who believe that a narrow-minded and ill-informed approach to HIV prevention is the way to overcome an epidemic that has now taken the life of more than 25 million people. In the past, there have been a number of people in positions of influence who have unreasonably complicated the path of HIV prevention, funding and policy.

A perfect example, and undeniably pertinent to the topic, is the church intervention in the recent statement by Pope Benedict XVI. The Roman Catholic Church has continued to promote an abstinence and faithfulness-only approach to HIV prevention in Africa, despite the evidence that confirms that this strategy cannot work within such a context. The African continent is the fastest growing region for the Roman Catholic Church, and is therefore significantly influenced by the position of the Church on matters such as HIV and AIDS. At the same time, the continent is also desperate for progress in the area of HIV prevention, which can only be achieved through the largescale implementation of proven-to-work strategies. This can help thorough the different sources as illustrated as shown;

\begin{tabular}{|l|l|l|}
\hline \multicolumn{3}{|c|}{ SOURCES OF STUDENTS INFORMATION } \\
\hline SOURCE & FREQUENCY & \% \\
\hline Electronic media & 25 & 35.7 \\
\hline Books and magazines & 20 & 28.6 \\
\hline Family members & 10 & 14.3 \\
\hline Friends & 11 & 15.7 \\
\hline Not stated & 4 & 5.3 \\
\hline Total & $\mathbf{7 0}$ & $\mathbf{1 0 0}$ \\
\hline
\end{tabular}


According to UNESCO's experience, education, and more specifically at school and university, is a keyinstrument in prevention. Specific information courses should be developed in Zambia, as anintegral part of the school curriculum on topics such as: life skills, the mutual respect and understandingof women and men and peer education. Practical information about body physiology, sex educationand the importance of protection (condoms) should be included in the curriculum. This effort needs to be reinforced, widened and made accessible to all school-age children throughout the world, within the context of basiclearning, using well adapted methods and contents, in other words, and culturally-appropriate education forall. In this respect, UNESCO's priorities concerning the reform of education in the perspective ofeducation for all throughout life will give priority to the development of secondary school education withemphasis on preventive education against HIV and AIDS with a specific focus on the identity.

\section{MEASURES FOR HUMAN IDENTITY RATHER THAN A SEX IDENTITY}

Finally, what measures can be employed in schools to ensure that girls and boys do not develop a sex or gendered identity but develop a human identity. Firstly, the curriculum has major role to play in enacting these measures. In the education system, there is a strong link between the curriculum and identity. There exists what is known as the hidden curriculum which mainly consists of the teacher student relationship. The hidden curriculum however, concerns everything that happens in the school that is not official. For instance, social relations in the class rooms, playgrounds, friendship, relationships between teachers and pupils, levels of bullying and harassment and so on. The hidden curriculum transmits to children a collection of messages which often reinforce sex stereotyping thus sustaining asexual division in society (kiloran\&Jemenez, 2007). Student's informal relations with the school are the most influential aspect of their socialisation into what it means to be male or female in society thus this aspect should be a priority in ensuring that girls and boys assume human identities.

This to a larger extent influences student's ideas about self and ultimately the formation of identity. Furthermore, the hidden curriculum has a pervasive influence on how teachers relate with fellow staff and ensure that students are motivated to do their best. Some of the characteristics of the hidden curriculum include the following, stated and unstated teacher expectorations from the students. Students are expected to behave and perform in a particular way by their teachers. This has a major influence on how they ultimately turn out and what identity they assume.

Further, the curriculum contains discipline practices, communication, and collaboration, problem solving and conflict management, norms among students and teachers. It also promotes human relationships between teachers and students. This is because students learn to treat and initiate contact from the school environment. Therefore, the school should provide a safe environment that encourages students to develop a human identity. This can only be done if educators are given opportunities for service training and development on gender identity issues.

Therefore, educators should be able to reflect on their personal assumptions and beliefs about gender roles in order to facilitate a non-judgmental learning environmental. Moreover, even when teachers believe that they treat students equally they are more likely to chastise male students and pay more attention to them. This creates a greater dependency in female students. Studies have shown that teachers tend to encourage passivity and conformity in female students and valuing independence in male students. Teachers allow males to be naughtier because they think it is natural for them to be mischievous. Therefore, in order to break stereotypes and promote human identities teachers should be aware of the fact that gender is an organising factor to a person assuming the desired identity (Seed, 2006).

Additionally, the school environment should be able to challenge gender norms. Policies that segregate by gender ignore and stigmatise individuals who challenge the typical male or female notions and can cause emotional and psychological distress for students. Educators should challenge gender norms in the classroom. With this in mind, the issue of single sex settings and co education has consequently shown that boys are given more attention by teachers in mixed schools. Teachers place more attention on boy's attendance than girls. Single sex schools allow boys and girls to choose freely subjects that they want. Single sex schools foresters the formation of human identity as opposed to gendered one. 
Another measure to be considered in addressing the issue of human identity is the type of school reading materials being used. The gendered nature of reading materials and other school texts books provide important indictors to the extent of gender stereotyping in the education system as a whole. In most books used in schools men appear or depicted more often and on a wider set of roles than women who assume the roles of domestic and romantic characters (Skelton, 1997). As a way of moving away from gendered or sex inclined identities, text books selected to be used in schools use illustrations that are non sexist and that language used is neutral. This measure is being affected in South Africa, Sweden and the United States of America.

Making sporting activities as mandatory for all pupils is yet another cardinal measure that should be observed. Pupils in schools should be given opportunities to choose what sports they like. The schools should have teams for girls and boys in all sporting activities. This will help foster a sense of identity and belonging. Above all boys and girls should be made to interact freely even as they play their particular sports. Activities such as physical education and sports days should be held on regular basis as part of the school curriculum. According to Freud (1959), there is a deep seated and pervasive belief that the effects on involvement in physical activities extend beyond the immediate fun and excitement of the moment. Many believe that physical activities especially play, games, sports provide an environment for acquiring culturally valued personal social attitudes, values, and behaviours and that what is learnt physically translates to other spheres of life. Play enables children to deal with anxiety evoking situations by allowing them to be the active masters of the situation other than passive victims.

In addition, one effective measure that can be taken by schools to ensure that girls and boys develop a human identity as opposed to a sex or gendered identity is sex education. Effective sex education is central to achieving this cause, since it equips pupils with necessary skills for avoiding negative health consequences. In the United States alone about 750,000 teens became pregnant every year. Sadly, 82 percent of those are unintended and half of the young people aged between 15 and 24 accounts for all HIV/ AIDS new infections and make up almost one half of over 19 million new sexually transmitted infections acquired in America each year (Youth, Risk behaviour Surveillance,2011). The statistics above are alarming and suggest urgent attention especially for third world countries which register far greater numbers than those observed above.

Sex education ensures that sex is delayed among pupils until they are ready. This is because it is inclined to emphasising abstinence as the only sure way of prevention from contracting the virus. When pupils are exposed to sex education they are able to distinguish between safe and unsafe relationships. There is positive communication among them as peers as they understand each other more. Improved conflict management also results from effective sex education. Ultimately, girls and boys develop human identities because they respect others in view of bodily autonomy. Girls and boys learn to show dignity regardless of orientation or gender identity. Sex education should be implemented by education boards in schools according to the learners' level of understanding and need. The material can be designed in such a way as to meet the growing demands of the learner as they progresses in their academic ladder. This is because developing identity is not a spontaneous process, it requires decisive measures.

Schools should begin to implement comprehensive sex education measures that are practical and evidence based. These measures should challenge the prevailing norms and values that are shrouded in ignorance and superstition especially with regards to sexuality. Peer groups can also be used by schools to help develop human identities among girls and boys. Pupils learn more from their peers. They easily accept ideas from those of their age group and constantly seek approval from their friends before they internalise what they observe. Peer groups can be school clubs such as anti Aids clubs, debate clubs and book clubs where a particular cohort meets to socialise.

According to Sen (2006), multicultural education emphasises that individuals do not have singular identities. Humans are included in several contexts such as family, social class, religion, gender, ethnicity, sexuality, sports all these aspects influence the identity formation process. Thus if girls and boys are to develop human identities there is need for the school to put in place measures that integrate all these aspects of life. 


\section{REFERENCES}

[1] Buchingham D Introducing identity, youth identity and digital media. Creative commons attribution. Massachusetts Institute of technology: 2008.

[2] Baumeister, F Identity, cultural change and struggle for self. New York: Oxford University press: 1986.

[3] United Nations United Nations youth,secretarygenerals report to the general assembly. [online] undesadsp.org/youth.Aspx 1981

[4] Laura D. Hanish and Richard AEarly socialisation. Arizona state university: 2014.

[5] Burke, Peter J. “Gender identity, sex, and school performance.” Social Psychology Quarterly 52: 1989.

[6] Gleitman, H., Fridlund, A. J. \&Reisberg, D. Basic Psychology. New York, NY: W. W. Norton \& Company, Inc: 2000.

[7] Giddens, A. Sociology. Cambridge, UK: Polity Press: 1993.

[8] B Kolucki 'Female Genital Mutilation: Disabling Women and Disabling Society,' http://www.disability world.org/01-03_04/women/fgm.shtml. Accessed 2 ${ }^{\text {nd }}$ April 2017:2007.

[9] Bachman, $\mathbf{J}$ and Omalley p self concept,self esteem and educational experiences. The frog pond revisited again. Journal of personality and social psychology: 1986.

[10] Baryado B Sex and the curriculum in Mexico and the United States: A heavy burden in ignorance. Washington DC: 1996

[11] Braddy, C\& Files, J Female Genital Mutilation: Cultural Awareness and Clinical Considerations, US: Elsevier: 2007.

[12] Carter, Gender socialisation, identity theory. Department of sociology. California state university. Northridge: 2014.

[13] Crespi L, Gender socialisation within the family: a study on adolescents and their parents in Great Britain. Catholic University. Milan. (2003).

[14] Egan, Kwhat is curriculum. Black well publishers: Canada.[online] www.blackwellpublishers.com: 1978

[15] Elliason Gendered socialisation between girls and boys in childrens football teams in sweden. [online]. Available at http//dx.doi.org/10/1080/14660. (2011).

[16] Gausser. Q. AIDS and Cultureal practice in Africa: the case of the Tonga (Zambia). Social science \& Medicine 52:509-518. 2001.

[17] Journal of HIV/AIDS Prevention \& Education for Adolescents \& Children Published online: 13 Nov 2009

[18] Kiloran L and Jimenez. PUnleashing the unpopular: talking about sexual orientation and gender diversity in education. Association for children education international: 2007.

[19] M Oak 'Characteristics of Culture,' L Walker, G Reid \& M Cornell (2004), 'Chapter 2: An Epidemic Waiting to Happen' in Waiting to Happen: HIV/AIDS in South Africa, pp. 60-87: 2008.

[20] Mackie $\mathrm{R}$ Male and female ability differences down to socialisation not Genetics. [Online] www.guardian.Com. Accessed 20 $0^{\text {th }}$ march 201:2010.

[21] Peterson, Gary W., and Della Hann. Socialising children and parents in families." In Handbook of Marriage and the Family, 2nd ed. Edited by Marvin B. Sussman, Suzanne K. Steinmetz and Gary W. Peterson. New York: Plenum Press:1999)

[22] RichardsonSocial and Economic studies.[online] www.jstor.org Accessed 20 ${ }^{\text {th }}$ march 2017:1982.

[23] Scottish executive education department. (2006) Review of strategies to address gender inequalities in schools. [Online] www.scottish.gov.com accessed on $20^{\text {th }}$ march 2017.

[24] Skelton,c., Revisiting Gender issues in reading schemes [online] www.skolverket.com accessed $20^{\text {th }}$ march 2017. (1997)

[25] UNESCO Division of Cultural Policies 1, rue Miollis 75732 Paris Cedex 15 Tel : + 33-1-45 684331 Fax : +33-1-45 685591 E-mail : culture.aids@unesco.orghttp://www.unesco.org/culture/aids

[26] Van Maanen, J., \& Schein, E. H. Toward a theory of organisational socialisation. Research in Organisational behavior, 1979.

[27] Young people and HIV/AIDS: Opportunity in crisis. UNAIDS web site: http://www.unaids.org/barce/ona/ presskit/youngpeople/index.html

[28] http://www.cirp.org/library/diseases/HIV/hrdy1/ Accessed on $28^{\text {th }}$ March 2017

[29] https://www.cdc.gov/hiv/group/age/youth/ . Accessed on 2 ${ }^{\text {nd }}$ April, 2017 


\section{AUTHORS' BIOGRAPHY}

Martin Banda, is a Lecturer for Sociology and is currently Head of Department of Educational Psychology and Sociology of Education at Kwame Nkrumah University-Zambia. He holds $\mathrm{PhD}$ and MA:Ed in Sociology of Education from the University of Zambia, a Bachelor of Arts with Education from the Catholic University of Eastern Africa. His research interests are Sociology of Education, Education and Society, The Teacher and the Community, Sex Education and Curriculum studies and Teacher Education.

Mable Nowanga Sitali Tembo, is a Lecturer for Educational Administration and Management and is currently Head of Department of Education Administration and Policy Studies at Kwame Nkrumah University-Zambia. She is a PhD candidate at the University of Zambia. She holds MA:Ed in Educational Management and Administration from the University of Zambia, Bachelor of Arts with Education from the University of Zambia. Her research interests are Educational Administration, Gender Issues in Education, Education and Society, Endogenous Systems of Knowledge and Teacher Education

Citation: Martin Banda, Mable Nowanga Sitali Tembo. "Secondary School Youths, Identity and the Curriculum. "International Journal of Humanities Social Sciences and Education (IJHSSE), vol 5, no. 8, 2018, pp. 66-81. doi: http://dx.doi.org/10.20431/2349-0381.0508009.

Copyright: (C) 2018 Authors. This is an open-access article distributed under the terms of the Creative Commons Attribution License, which permits unrestricted use, distribution, and reproduction in any medium, provided the original author and source are credited. 